\title{
Estimation of the Technical State of Automotive Disc Brakes Using Fuzzy Logic
}

\author{
M. Baban, C.F. Baban, C. Bungau, G. Dragomir, R.M. Pancu
}

\author{
Marius Baban, Calin Florin Baban*, \\ Constantin Bungau, George Dragomir, Rares Mihai Pancu \\ University of Oradea, Romania, Oradea, Universitatii st., 1 \\ mbaban@uoradea.ro, bungau@uoradea.ro, \\ georgedragomir@yahoo.com, pancurares@yahoo.com \\ *Corresponding author: cbaban@uoradea.ro
}

\begin{abstract}
According to existing studies the phenomena that occur in the exploitation of the braking system are very complex and an analytical mathematical modeling of braking process it is difficult to be developed [1]. Since these phenomena are also characterized by some uncertainties, a fuzzy logic approach has been employed in this research for the estimation of technical state of the disc brakes. Their technical state was expressed through the thickness variation, which was used as the output linguistic variable. The vibrations and temperature of the disc brakes were used as the input linguistic variables. The fuzzy decision system for the estimation of technical state of the disc brakes has been implemented with the Fuzzy Logic Toolbox ${ }^{T M}$ of the Matlab ${ }^{\circledR}$ software, which can be employed to determine if the thickness of the disc brakes becomes smaller than the limit value prescribed by the manufacturer.

Keywords: disc brake, temperature, vibration, thickness variation, fuzzy logic approach.
\end{abstract}

\section{Introduction}

Throughout the exploitation of the disc brake its thickness is modified in the contact interface with the friction material of the brake pads, due to the effect of wear. If the thickness of the disc brake becomes smaller than a certain limit value prescribed by the manufacturer, the probability of the deformation of the disc brake or even its damage is increasing at the high intensity or long duration of braking. This may have serious implications for the road accidents.

The replacement of discs and brake pads depends on the number of traveled kilometers and it is usually done preventively, when periodic revisions are carried out. Such replacement can occur even if maximum wear is not reached, which leads to higher exploitation costs due to unused of disc brakes for their entire lifetime. On the other hand, there may be situations where disc brakes reach maximum wear before a periodic revision is scheduled, because of some exploitation conditions that require a more intense use of the braking system of the vehicle.

Due to the complexity of the phenomena that occur in the exploitation of the braking system, phenomena that are influenced by different factors [7] and are characterized by some uncertainties, an analytical mathematical modeling of braking process it is difficult to be developed [1]. During the braking process, vibrations are produced within the contact area between the discs and brake pads and their spectrum depends on factors such as the degree of wear and temperature. Studies on vibrations in the car braking system are presented in ( [13], [15], [16]), while investigations about the temperature of disc brakes are shown in ( [3], [8], [23]).

The employement of fuzzy logic in automotive engineering has been presented in different studies. Von Altrock [20] emphasized the use of fuzzy logic for the ABS systems, control of the engine and control of automatic transmission. The control of the braking system, the suspension control and the vehicle dynamics control are presented among the relevant research areas of fuzzy control in automotive field ( [9]). The use of fuzzy logic for the ABS systems has been shown 
in other studies ( [5], [11], [21], [22]). Fuzzy logic was also used to improve the handling and stability of vehicles ( [4], [18]), to control the speed of an automotive engine ( [19]) or to control a suspension system of automotive ( [6]).

While fuzzy logic in automotive field has been used lately, its employement for the estimation of technical state of the disc brakesis is still a challenging approach and this area of research is less developed. Within this framework, the fuzzy logic ( [12], [14], [17]) has been proposed for the estimation of technical state of the disc brakes, so they can be replaced before the maximum limit of wear is reached and without depending on the planned periodic revisions.

The research begins with the description of the experimental stand developed for the estimation of the technical condition of disc brakes. A fuzzy logic decision approach for the estimation of technical state of the disc brakes is shown in the next section. The implementation of the fuzzy logic decision approach for the estimation of technical state of the disc brakes with the Fuzzy Logic Toolbox ${ }^{T M}$ of the Matlab ${ }^{\circledR}$ software is also depicted. At the end, conclusions and recommendations for future research are presented.

\section{Experimental method}

For the estimation of the technical condition of disc brakes, the stand depicted Fig. 1 has been developed. The stand is based on a powertrain that consists of the following main elements: a) four cylinders diesel engine with the following characteristics: maximum power $43.5 \mathrm{~kW}$ at $4600 \mathrm{rot} / \mathrm{min}$, maximum torque $110 \mathrm{Nm}$ at $2000 \mathrm{rot} / \mathrm{min}$;

b) gearbox 5-speed manual transmission;

c) MacPherson front suspension;

d) hydraulic brake system composed of:

- a master brake cylinder, operated by a screw to ensure precise movement of the piston within its interior;

-a brake pipe and a brake caliper;

-a full disc brake with the diameter of $247 \mathrm{~mm}$;

-brake pads.

The FLIR SC 640 infrared camera was used to monitor the temperature of braking disc. The vibration monitoring was performed with a system composed of PC-TopMessage device (made by Delphin Technology AG)-accelerometer sensor. The fluid pressure in the hydraulic circuit was monitored through a manometer with glycerin (scale $0 \ldots 6 \mathrm{MPa})$. The speed rotation of the disc brake (expressed in $\mathrm{km} / \mathrm{h}$ ) was monitored by a speedometer.

The contact force between the brake pads and disc was kept constant by maintaining the pressure of the brake pipe fluid at $1 \mathrm{MPa}$. The disc rotation speed was also maintained constant at a value corresponding to vehicle speeds of $30 \mathrm{~km} / \mathrm{h}$. The first speed of the gearbox was used to provide an engine speed in the stable operation area, without trepidation that could affect the vibrations measurement. Due to the dilatation of the material of the disk brake as a result of increasing its temperature during the braking process, we proceeded to fine tune of the position of the piston in the brake master cylinder using a screw-nut mechanism to maintain constant the pressure of the brake fluid.

The experiments were conducted using two disc brakes, corresponding to a new disc (thickness $=10 \mathrm{~mm}$ ) and to a disc with the thickness at the lower limit prescribed by the manufacturer (thickness $=8.5 \mathrm{~mm})$. 


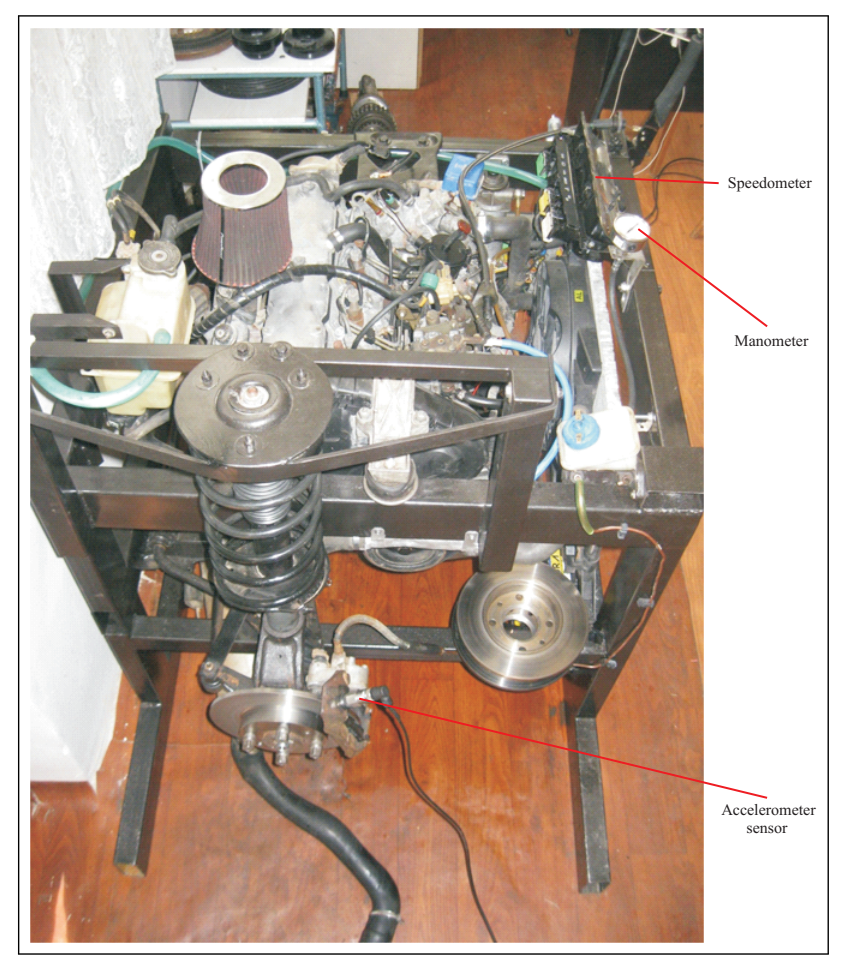

Figure 1: The experimental stand for the estimation of the technical condition of disc brakes

\section{Results}

A lowest value of the vibration amplitude equal to $1.46 \mathrm{~mm} / \mathrm{s} \mathrm{rms}$ was measured for a new disc brake (thickness $=10 \mathrm{~mm}$ ) at a temperature of $50.9{ }^{0} \mathrm{C}$. A highest value of the vibration amplitude equal to $2.4 \mathrm{~mm} / \mathrm{s} \mathrm{rms}$ was measured for a disc brake with the thickness of $8.5 \mathrm{~mm}$ at a temperature of $154.2{ }^{\circ} \mathrm{C}$.

The fuzzy logic decision approach described in [2, p.22-23] was employed for the estimation of technical state of the disc brakes, as follows:

1) The $\mathrm{T}=$ temperature $\left[{ }^{0} \mathrm{C}\right]$ and Avib=Vibration's amplitude $[\mathrm{mm} / \mathrm{s}] \mathrm{rms}$ were used as the input linguistic variables:

$$
L V_{I}=\left\{T, A_{v i b}\right\}
$$

Considering the measured value of the $\mathrm{T}$ and Avib, their domain values have been defined as follows:

$$
\begin{array}{r}
T: D_{T}=[50.9,154.2] \\
A_{v i b}: D_{A_{v i b}}=[1.46,2.4]
\end{array}
$$

2) For the $T$ and Avib variables the linguistic terms have been established as:

$$
T: L T^{T}=\left\{\begin{array}{c}
\text { Tverysmall } \\
\text { Tsmall } \\
\text { Tmedium } \\
\text { Tbig } \\
\text { Tverybig }
\end{array}\right\}
$$


and

$$
\text { Avib :LT } T^{\text {Avib }}=\left\{\begin{array}{c}
\text { AVverysmall } \\
\text { AV small } \\
\text { AVmedium } \\
\text { AVbig } \\
\text { AVverybig }
\end{array}\right\}
$$

Among the membership functions, the triangular functions are extensively employed and they have been proposed as the membership functions for both $\mathrm{T}$ and Avib variables. According with the definition of [10, p.25], their expressions are:

$$
m f_{k}^{T}\left(x, a_{T_{k}}, b_{T_{k}}, c_{T_{k}}\right)=\left\{\begin{array}{ll}
0, & x \leq a_{T_{k}} \\
\frac{x-a_{T_{k}}}{b_{T_{k}}-a_{T_{k}}}, & a_{T_{k}} \leq x \leq b_{T_{k}} \\
\frac{c_{T_{k}}-x}{c_{T_{k}}-b_{T_{k}}}, & b_{T_{k}} \leq x \leq c_{T_{k}} \\
0, & c_{T_{k}} \leq x
\end{array}, k=1 \ldots 5\right.
$$

and

$$
m f_{j}^{A v i b}\left(x, a_{A v i b_{j}}, b_{A v i b_{j}}, c_{A v i b_{j}}\right)=\left\{\begin{array}{ll}
0, & x \leq a_{A v i b_{j}} \\
\frac{x-a_{A v i b_{j}}}{b_{A v i b_{j}-a_{A v i b}}}, & a_{A v i b_{j}} \leq x \leq b_{A v i b_{j}} \\
\frac{c_{A v i b_{j}}-x}{c_{A v i b_{j}}-b_{A v i b_{j}}}, & b_{A v i b_{j}} \leq x \leq c_{A v i b_{j}} \\
0, & c_{A v i b_{j}} \leq x
\end{array}, j=1 \ldots 5\right.
$$

where:

- $a_{T_{k}}<b_{T_{k}}<c_{T_{k}}$ are the parameters of each triangular membership function $m f_{k}^{T}$ in the expression (5), $\mathrm{k}=1 \ldots 5$;

- $a_{A v i b_{j}}<b_{A v i b_{j}}<c_{A v i b_{j}}$ represent the parameters of each triangular membership function $m f_{j}^{A v i b}$ in the expression (6), $\mathrm{j}=1 \ldots 5$.

3) The $\mathrm{TBD}=$ the thickness of the brake disc $[\mathrm{mm}]$ was employed as the output variable:

$$
L V_{O}=\{T B D\}
$$

For the TBD variable, the domain value has been defined as:

$$
T B D: D_{T B D}=[8.5,10]
$$

4) For the TBD variable the linguistic terms have been established as:

$$
T B D: L T^{T B D}=\left\{\begin{array}{c}
\text { TBDverysmall } \\
\text { TBDsmall } \\
\text { TBDmedium } \\
\text { TBDbig } \\
\text { TBDverybig }
\end{array}\right\}
$$


The triangular function have also been proposed as the membership function for TBD variable and its expression is [10, p.25]:

$$
m f_{r}^{T B D}\left(x, a_{T B D_{r}}, b_{T B D_{r}}, c_{T B D_{r}}\right)=\left\{\begin{array}{ll}
0, & x \leq a_{T B D_{r}} \\
\frac{x-a_{T B D_{r}}}{b_{T B D_{r}}-a_{T B D_{r}}}, & a_{T B D_{r}} \leq x \leq b_{T B D_{r}} \\
\frac{c_{T B D_{r}}-x}{c_{T B D_{r}}-b_{T B D_{r}}}, & b_{T B D_{r}} \leq x \leq c_{T B D_{r}} \\
0, & c_{T B D_{r}} \leq x
\end{array}, r=1 \ldots 5\right.
$$

where $a_{T B D_{r}}<b_{T B D_{r}}<c_{T B D_{r}}$ represent the parameters of each triangular membership function $m f_{r}^{T B D}$ in the expression (10), $\mathrm{r}=1 \ldots 5$.

5) The fuzzy rules base is:

$$
\begin{aligned}
& \text { Rule }_{1}:\{\text { IF (AVverysmall) and (Tverysmall) then (TBDverybig) }\} \\
& \text { Rule } 2:\{I F \text { (AVverysmall) and (Tsmall) then (TBDverybig) }\} \\
& \text { Rule }_{3}:\{I F \text { (AVsmall) and (Tverysmall) then (TBDverybig) }\} \\
& \text { Ruleg }^{\text {: }}\{\text { IF (AVmediu) and (Tmedium) then (TBDmedium) }\} \\
& \text { Rule }_{23}:\{I F \text { (AVverybig) and (Tbig) then (TBDverysmall) }\} \\
& \text { Rule }_{24}:\{I F \text { (AVbig) and (Tverybig) then (TBDverysmall) }\} \\
& \text { Rule }_{25}:\{\text { IF (AVverybig) and (Tverybig) then (TBDverysmall) }\}
\end{aligned}
$$

6) The centroid method [17, p. 98] has been used to obtain the the defuzzified value TBD of the thickness of the disc brake.

The fuzzy logic decision approach for the estimation of technical state of the disc brakes has been implemented with the Fuzzy Logic Toolbox ${ }^{T M}$ of the Matlab ${ }^{\circledR}$ software (Fig. 2). The inference rules are shown in figure 3. Figure 4 depicts the dependence of the $T B D=f(T$, Avib). Considering $\mathrm{T}=116{ }^{\circ} \mathrm{C}$ and Avib $=2.16 \mathrm{~mm} / \mathrm{s} \mathrm{rms}$ we obtain $\mathrm{TBD}=8.9 \mathrm{~mm}$, so that thickness of the disc brake is within prescribed limits $[8.5,10]$. 


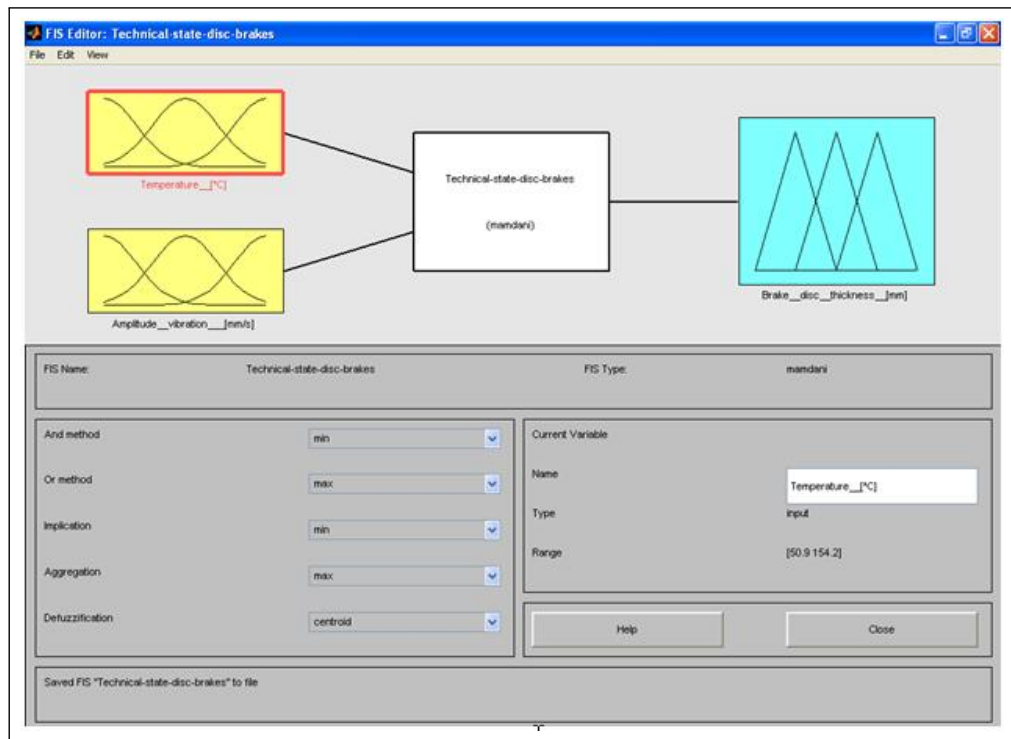

Figure 2: The fuzzy decision system Technical-state-disc-brakes.fis

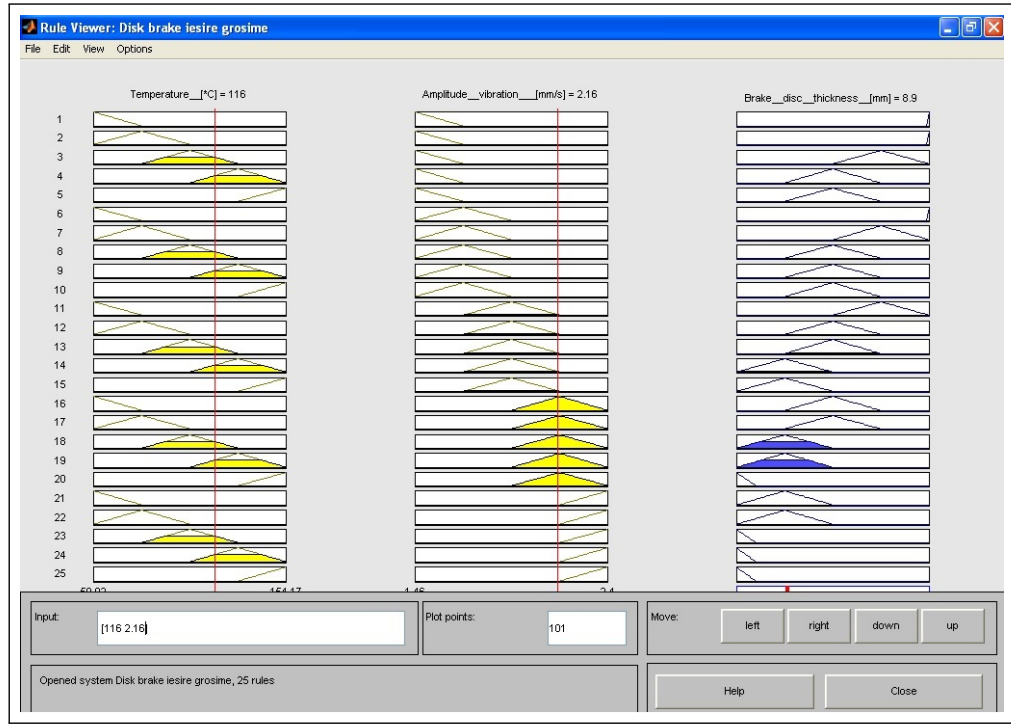

Figure 3: The inference rules of the fuzzy decision system Technical-state-disc-brakes.fis

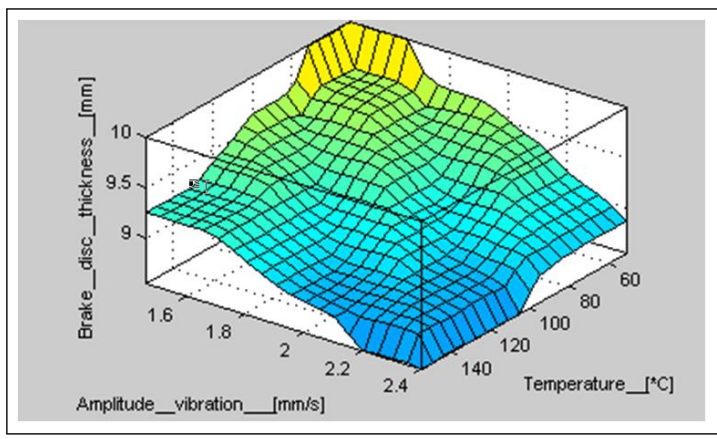

Figure 4: The dependence $\mathrm{TBD}=\mathrm{f}(\mathrm{T}$, Avib $)$ 


\section{Conclusions}

The phenomena that occur in the exploitation of the braking system are very complex and they are characterized by some uncertainties. Therefore, a fuzzy logic approach has been employed in this research for the estimation of technical state of the disc brakes, expressed through their thickness variation.

A stand has been developed to establish the domain values of the temperature and vibration amplitude of the disc brakes, which were used as the input linguistic variables. The thickness of the disc brakes was employed as the output linguistic variable. The Fuzzy Logic Toolbox ${ }^{T M}$ of the Matlab ${ }^{\circledR}$ software was used to develop the fuzzy decision system, which can be applied to establish if the thickness of the disc brakes is within prescribed limits by the manufacturer.

In our research both the contact force between the brake pads and disc, and the disc rotation speed were maintained constant. Future studies are needed to investigate the development of a fuzzy decision system when these two characteristics are also variable. The use of fuzzy logic approach in joining with other artificial intelligence methods, including neural networks may also represent important area for future research.

\section{Bibliography}

[1] Aleksendric, D.; Barton, D. C. (2009); Neural network prediction of disc brake performance, Tribology International, 42(7): 1074-1080.

[2] Baban, M.; Baban, C.F.; Blaga, F.S. (2010); Maintenance planning of cold plastic deformation tools using fuzzy logic, Eksploatacja i Niezawodnosc- Maintenance and Reliability, 3: $21-26$.

[3] Belhocine, A.; Bouchetara, M. (2012); Thermomechanical modelling of dry contacts in automotive disc brake, International Journal of Thermal Sciences, 60: 161-170.

[4] Boada, M.J.L.; Boada, B.L.; Munoz, A.; Diaz, V. (2006); Integrated control of front-wheel steering and front braking forces on the basis of fuzzy logic, Proceedings of the Institution of Mechanical Engineers 220.D3 (Mar 2006), 253-267.

[5] Cabrera, J.A.; Ortiz, A.; Castillo, J.J.; Simon, A. (2005); A Fuzzy Logic Control for Antilock Braking System Integrated in the IMMa Tire Test Bench, IEEE Transactions on Vehicular Technology, 54(6):1937- 1949.

[6] Cherry, A.S.; Jones, R.P.(1995); Fuzzy logic control of an automotive suspension system, IEE Proceedings: Control Theory and Applications, 142(2):149-160.

[7] Cirovic, V.; Aleksendric, D. (2011); Dynamic modelling of disc brake contact phenomena, FME Transactions, 39(4):177-183.

[8] Hwang, P.; Wu, X. (2010); Investigation of temperature and thermal stress in ventilated disc brake based on 3D thermo-mechanical coupling model, Journal of Mechanical Science and Technology, 24:81-84.

[9] Ivanov, V. (2010); Fuzzy Methods in Ground Vehicle Engineering: State-of-the-Art and Advanced Applications, Proceedings of the 8th International Conference on Structural Dynamics, EURODYN 2011 Leuven, Belgium, 4-6 July 2011, G. De Roeck, G. Degrande, G. Lombaert, G. Muller (eds.), 3008-3015. 
[10] Jang, J.-S.R.; Sun, C. T.; Mizutani, E. (1997); Neuro-Fuzzy and Soft Computing: A Computational Approach to Learning and Machine Intelligence, Upper Saddle River, NJ: PrenticeHall.

[11] Mauer, G.F. (1995); A fuzzy logic controller for an ABS braking system,IEEE Transactions on Fuzzy Systems, 3(4):381-388.

[12] Ross, T. (2004); Fuzzy Logic with Engineering Applications, John Wiley \& Sons Ltd., second edition.

[13] Sawczuk, W. (2011); Application of vibroacoustic signal to diagnose disck braking system, Journal of KONES Powertrain and Transport, 18 (1): 525-534.

[14] Seising, R. (2011); From Electrical Engineering and Computer Science to Fuzzy Languages and the Linguistic Approach of Meaning: The non-technical Episode: 1950-1975, International Journal of Computers Communications \& Control, 6(3): 530-561.

[15] Sergienko, V. P.; Bukharov, S. N. (2009); Vibration and Noise in Brake Systems of Vehicles. Part 2: Theoretical Investigation Techniques, Journal of Friction and Wear, 30(3): 216-226.

[16] Sergienko, V. P.; Bukharov, S. N.; Kupreev, A. V.(2008); Noise and Vibration in Brake Systems of Vehicles. Part 1: Experimental Procedures, Journal of Friction and Wear, 29(3):234241.

[17] Sivanandam, S.N.; Sumathi, S.; Deepa, S.N. (2006); Introduction to Fuzzy Logic using MAT$L A B$, Springer.

[18] Song, J.(2012); Integrated control of brake pressure and rear-wheel steering to improve lateral stability with fuzzy logic, International Journal of Automotive Technology, 13(4): 563-570.

[19] Vachtsevanos, G.J.; Farinwata, S.S.; Pirovolou, D.K. (1993); Fuzzy logic control of an automotive engine, IEEE Control Systems, 11(3): 62-68.

[20] von Altrock, C.(1997); Fuzzy Logic in Automotive Engineering, Circuit Cellar INK, The Computer Applications Journal, 88: 1-9.

[21] Will, A.B., Zak, S.H. (2000); Antilock brake system modelling and fuzzy control, International Journal of Vehicle Design, 4(1): 1-18.

[22] Yazicioglu, Y.; Unlusoy, Y.S. (2008); A fuzzy logic controlled Anti-lock Braking System (ABS) for improved braking performance and directional stability, International Journal of Vehicle Design, 48(3-4): 299-315.

[23] Yevtushenko, A.; Kuciej, M. (2010); Temperature and thermal stresses in a pad/disc during braking, Applied Thermal Engineering, 30: 354-359. 